\title{
'Unlearning Privileges': Interrupting Pre-Service Teachers Deficit Thinking of Immigrant Students with Origins in the South
}

\author{
Yan Guo \\ University of Calgary \\ yanguo@ucalgary.ca
}

\begin{abstract}
Drawing from critical and postcolonial theoretical perspectives, this paper demonstrates how a teacher educator has implemented some experiential strategies in order to encourage pre-service teachers to challenge their largely unexamined, deficit thinking regarding their English as an Additional Language (EAL) students. Teacher educators preparing teachers to work effectively and equitably in a linguistically, culturally and racially diverse context can employ teaching strategies described in this paper.
\end{abstract}

\section{Introduction}

I think that for the most part, immigrant students are seen as immigrants first and students second - that their being is defined principally in terms of difference... I think that the wider societal perception of immigrant students is that these students are in some way deficient in being fully able to participate in the dominant culture - that there is an implicit 'disconnect' with the nuances of native spoken language; while I know this is not the case for these students, I have seen evidence of this perception ${ }^{i}$. (online reflection by a pre-service teacher)

The above quote illustrates the identification by a pre-service teacher of deficit thinking, evident in dominant social, cultural, and institutional narratives that underpin the representations of immigrant students in the literature, media, curriculum documents, and in teachers' daily interactions with immigrant students.

Beginning in 2003, I became a teacher educator at the undergraduate and graduate levels. Throughout this 11-year period I have developed and facilitated purposeful educational experiences in all of my courses which are intended to challenge pre-service and in-service 
educators to rethink and reconceptualize the ways in which schools develop and structure formal and informal educational policies regarding 'the position' meaning the ranking, rating and valuing/devaluing of immigrant, English as an Additional Language (EAL). Drawing from critical and postcolonial theoretical perspectives and further exemplified with the inclusion of examples from my earlier study (Guo, 2012a, 2012b) and university teaching of pre-service teachers, this paper demonstrates how I have implemented some experiential strategies in order to encourage pre-service teachers to challenge their largely unexamined, deficit thinking regarding their EAL. Teacher educators preparing teachers to work effectively and equitably in a linguistically, culturally and racially diverse context can employ teaching strategies described in this paper.

\section{Context: National and local snapshots}

Immigration is now the main source of Canada's population growth. This has significant implications for Canadian school systems, and for the preparation of teachers. According to the 2011 Census, almost 6.6 million people, that is, about one out of every five people in Canada, speaks a language other than English or French as their mother tongue (Statistics Canada, 2012). Moreover, the long-term prospect for this population is continued growth (Statistics Canada, 2010). Calgary is the largest recipient of immigrants and English as an additional language (EAL) students in Alberta, and the fourth largest such urban area in Canada, after Toronto, Vancouver, and Montreal. The number of EAL students in schools is growing rapidly. In Alberta, for example, there were 14,673 EAL students enrolled in provincial schools in 1989 - a figure that rose to 79,981 in 2013 (Alberta Education, 2013). The Calgary Board of Education enrolled about 26,637 EAL learners in 2013, which currently represents over $25 \%$ of the total student population in the public board. It is a typical enrolment pattern that is found in other provinces such as British Columbia (Ilieva, 2013).

Given the increasing linguistic and cultural diversity of the Canadian population, existing teacher education programs cannot prepare sufficient numbers of teacher specialists for the EAL school population. This strongly suggests that all teachers need to be prepared to teach the EAL population. The preparation of teachers, however, has not yet caught up to these demographic changes. Pre-service teachers still tend to be white, middle-class, female and monolingual (Hodgkinson, 2002). Today's immigrant students are mostly from Asia, Africa, the Middle East, 
Central and South America, and the Caribbean (Statistics Canada, 2013). This cultural, racial, and linguistic divide between teachers and students has major implications for appropriate teacher education. Most teacher preparation programs, however, neglect the needs of EAL students. Indeed, most classroom teachers have not received the preparation required to help EAL learners achieve their best. As Garnett (2012, p. 18) noted: "Even after nearly two decades of large scale immigration, many mainstream teachers retain two characteristics: (a) inadequate training for meeting the needs of ESL students, and (b) the related belief that ESL students are not their responsibility." A report on ESL education in Ontario states: "The state of ESL in large, multi-ethnic school boards is abysmal, and, in essence, a betrayal of the public trust. The reality is that ESL students are denied access to supports necessary for their academic success" (Meyer, 2003, p.3).

\section{Critical examination of deficit thinking: a synthesis}

EAL students bring their languages, cultures, religions, and educational backgrounds to our schools, enriching our educational environments. However, many pre-service teachers use deficit-oriented discourses, highlighting EAL students' inability to speak English and their difficulties in communicating in schools. Deficient thinking includes overgeneralizations about: students' family backgrounds, having very low expectations of students' achievements, creating caring classroom environments often, at the expense of students' academic successes, and as importantly, holding mainstream monocultural views of appropriate childrearing practices and criteria for school success. Many pre-service teachers believe that many of their EAL students' educational risks and vulnerabilities could be linked to adverse sociocultural factors such as poverty, limited English proficiency, and racial or ethnic minority status. For example, some student teachers made comments such as: "Today a lot of these kids are from immigrant homes. They have parents who don't speak English" (Guo, 2012b). As such, these generalizations perpetuate the traditional missionary perspective that EAL children and families are deficient and in need of remediation. Deficit thinking about immigrants and their children permeates mainstream society, and is largely mirrored in public schools.

It is important for teacher educators to engage student teachers to actively resist deficit perceptions of EAL learners, whereby "the inability to speak standard English is oftentimes equated with low levels of cognitive functioning" (Goodwin \& Macdonald, 1997, p. 212). In my 
university classes, we discuss how difference is perceived as deficit, and how that leads to devaluation of EAL children's and their families' knowledge (Guo, 2009). Accordingly, the rich cultural, linguistic, and religious knowledge of EAL students is often unrecognized by teachers and school administrators (Cummins et al., 2005). These forms of non-recognition of immigrant students prior knowledge, is similar to the non-recognition of their parents' educational qualifications, and expertise in the workplace (Guo, 2009). Deficit thinking can be attributed to misconceptions of difference, and lack of knowledge about different cultures (Guo, 2009; Honneth, 1995). A deficit model of difference leads to the belief that difference is equal to deficiency, and that the knowledge of others - particularly those from developing countries - is incompatible, inferior, and hence invalid (Abdi, 2007; Dei, 1996). If pre-service teachers hold these attitudes, even tacitly, they may fail to recognize and make use of EAL students' prior knowledge.

Some pre-service teachers, indeed, recognize the importance of critical self-examination. One student teacher stated, quite rightly:

I think the starting point for good teaching is to turn a critical eye inward and become aware of our assumptions and where they are coming from. (online reflection)

As MacPherson et al. (2004) suggest, teachers need to develop the ability to move "across cultures in a way that is tolerant of conflicting perspectives and deeply respectful of people's lived differences" (p. 5). This ability requires that teachers move beyond learning about other groups to reach the stage of examining the cultural contexts that have influenced their own behavior, attitudes, and beliefs (Mujawamariya \& Mahrouse, 2004; Solomon \& Levine-Rasky, 2003).

\section{Feeling unprepared}

Some pre-service teachers in an earlier study (Guo, 2012b) were shocked to see the large number of EAL students in the schools to which they were assigned for their practicum (field experiences):

My school was almost on the border between the southeast and northeast. I would describe the area as fairly low socio-economic, transient, and with a high immigrant 
population. The school population was about 300 children from preschool through grade 3. The school has about $70 \%$ of its population considered ESL. In my own classroom I came up with a number of $69 \%$. (online reflection)

My school was in the central NW with a primarily middle to low upper-class population. There were about 600 students with $80-90 \%$ ESL population overall. My classes reflected those numbers. (online reflection)

Pre-service teachers commented that there was not enough training offered in teaching EAL in their on-campus courses. Similar findings were reported in other studies (Batt, 2008; Flores \& Smith, 2008; O’Neal, Ringler \& Rodriguez, 2008). O’Neal, Ringler and Rodriguez (2008)’s interviews of 24 rural elementary teachers in North Carolina indicated that the teachers' perceptions were that instruction in teaching EAL was not important in their teacher preparation and they were not being adequately prepared to teach EAL students.

Many pre-service teachers in my study (Guo, 2012b) reported that they felt helpless because they did not know how to support EAL children. For example, one pre-service teacher reported:

I had a student come into my grade 3 classroom in my first year practicum from Poland partway into the school year. This poor student was given very little support from my partner teacher and was reduced to reading baby-books with pictures to help him to learn some of the basic vocabulary. This student did not speak a word within the school setting (not in English or Polish) and yet was very much present behind his eyes. I always wondered how we could reach him, how we could incorporate him within our classroom without dumbing him down or making him look stupid. I always knew that he understood more than he was letting on, but felt that he was afraid to open up or attempt English in class for fear of ridicule for mistakes. I wanted so badly to be able to give him some sort of support so that he could make connections within the classroom and the curriculum but it was very challenging, especially as time went on and he began to show behaviour issues within the room as he was no doubt frustrated and angry with us. (online reflection)

Some pre-service teachers felt overwhelmed. One pre-service teacher wrote: 
The idea of teaching a child that is recently immigrated to Canada was frightening and often brought along some anxiety as a teacher. How could I communicate with a child who does not speak English? How would I handle the language barrier? (Guo, 2012b)

Some pre-service teachers chose to ignore EAL students and furthermore, perceived the difficulties faced by EAL students as evidence that there is something wrong with these students. One stated:

Having always been a member of the dominant language group, they did not have the experience of having to learn and communicate in a language they are completely unfamiliar with. Furthermore, because of privilege, they were able to ignore rather than empathize with ESL students. There was an idea that they could improve their situation without much difficulty... They see these difficulties faced by ESL students as evidence that there is something wrong with them. (online reflection)

In my university teaching, I often used a language shock activity to challenge pre-service teachers to better understand what it feels like to be an EAL student. The students were asked to follow my directions in Chinese in an activity. They were also asked to observe their peers' physical reactions and share their emotional responses at the end of the activity. I noticed that some of them very quickly, became frustrated and asked me if I could switch to English. This language shock activity provided an opportunity for the student teachers to experience firsthand what it was like to be an EAL student. In the course evaluation, students commented "I didn't truly feel what it was like for EAL students to sit and learn in class until Yan forced us into that situation." Another student commented that "rather than talk about how "it's hard for immigrant students to fit in without English", she [Yan] would do class exercises in other languages so we really feel the exclusion that the students feel." Another student reported: "I really liked the activity where she [Yan] spoke Mandarin to us as a class because it helped show how difficult it is to be a new EAL student." I also hoped that they would become more sensitive to their students' dilemmas when later addressing the affective needs of their own EAL students.

\section{Challenging discrimination of southern accents}

One of the major dilemmas is that some EAL children speak English with nontraditional accents. Accordingly, despite significant differences in regional accents in Canada, USA, and 
UK, such differences are allowed. Interestingly, it is the accents from the southern countries which are highlighted, and perceived to be different from the standard Canadian English accent spoken on CBC. Difference, is unfortunately, perceived to be a marker of unintelligence. This is evident in the following reflections by the pre-service teachers in my earlier study:

For example, if I am teaching a student with a strong accent, I find myself generalizing that the students' English comprehension may in some way lack fluency. I know that this is not the case, but I cannot help changing the way in which I speak to these students. I think that the wider societal perception of immigrant students is that these students are in some way deficient in being fully able to participate in the dominant culture- that there is a implicit 'disconnect' with the nuance of native spoken language. (online reflection)

Regarding language issues and communicating with those whom I didn't share the same language with, I often had to fight with my first feeling that, because someone did not respond appropriately or use simpler language, that they were somehow less intelligent. I was embarrassed when I realized that I thought this way and even more embarrassed when I felt my relationship improved when the other person's English improved. (online reflection)

In challenging the notion that accents are equated with unintelligence, I invited the student teachers to read an essay "Mother Tongue" by Amy Tan (1990), a well-known American writer. In this essay Tan recalls that when she was young she felt ashamed of her mother's English. She was embarrassed because she usually, had to accompany her mother to her appointments, and translate for her. Much later she realized that her mother's "broken" English was not a marker of unintelligence. On the contrary, her "simple" English reveals "her intent, her passion, her imagery, the rhythms of her speech and the nature of her thoughts" (Tan, 1990, n.p.). Eventually, Tan claimed her mother's linguistic and cultural heritage with pride. She realized that it was not her mother who was unintelligent, but the false stereotype of immigrants held by the larger society. I used this essay in order to, raise the following questions with the class: Why was Tan ashamed of her mother's English when she was young? In your field experience, did you think that EAL students felt ashamed of their English accents? What did you do to support EAL students? What made Tan change her perception of her mother's English? 
Explain what Tan means by "different Englishes." Describe the differences between the way Tan viewed her mother's "simple" English, in contrast with, the way the rest of society viewed her mother's "broken" English. How did Tan struggle with these conflicting views?

As importantly, I also read a key part of Amy Tan's (1989) novel, The Joy Luck Club with the class. Rose, the American-born daughter, like her mother, sacrifices her own desires in order to make her husband happy. But one day her husband, Ted, grows tired of her and makes his final decision-to divorce her. Rose, is suddenly abandoned, without her husband, the decision-maker, she does not know what to do. She goes to a psychiatrist for help, which her mother thinks is quite foolish. She tells her daughter that "a mother is best. A mother knows what is inside you... a psyche-atricks will only make you hulihudu（or hulihutu 糊里糊涂）, make you see heimongmong (or heimengmeng 黑蒙蒙)” (p. 210). Rose's mother uses Chinese expressions not only to preserve her right to speak Chinese, but also to suggest to her daughter that her Chinese way of thinking is better than that of Rose's American trained psychiatrist. The Chinese expressions also enable an important cultural connection between mother and daughter. To her surprise, Rose realizes that "it was true. Lately I had been feeling hulihudu . And everything around me seemed to be heimongmong. These were words I had never thought about in English terms. I suppose the closest meaning would be 'confused' and 'dark fog"' (p. 210). Rose's mother has thus been able to point out what is wrong with her daughter, namely, that Rose is disoriented because she has lost her lodestar/polestar, her fixed point of reference, her husband. In order to help her daughter to learn to make a choice for herself, Rose's mother tells her daughter about her own life in China. She tells her how she learned to shout at those who tried to silence her. She simply asks her daughter: "Why do you not speak up for yourself?” (p. 216). After having learned her mother's story, Rose comes to understand the significance of finding one's voice. Later she listens to her mother and learns to shout, too. She realizes that for fifteen years she had lived in the shadow of her husband and has lost her own voice. She has been contented with not having a say for herself. Now she hears her own voice again as she tells Ted firmly: "You can't just pull me out of your life and throw me away" (p. 219). I used this dialogue as an example to demonstrate how the Chinese mother's playful and creative pun, 'psyche-atricks', and the use of her Chinese words explicitly reveal her 
intent, her sense of humour, and her wisdom. This effectively, dispels societal stereotypes which link intelligence and one's accent.

\section{English only and resultant devaluation of students' first language}

As stated earlier, the local public school board had more than 26,637 EAL students, currently representing about $25 \%$ of student population. There were at least 140 different languages spoken by the EAL students. The languages most spoken at home by EAL families were Arabic, Cantonese, Mandarin, Punjabi and Urdu (in an undergraduate course in 2014) Despite multilingual realities, "our school system, from curriculum to assessment to teacher preparation is predicated on a monolingual bias" (online reflection). Several schools adopted an English only policy, evident in the following statements:

One of the school rules is ENGLISH ONLY throughout the entire building. Students have received lectures from various members of administration for not speaking English in the common areas or in classrooms on their break time. Teachers also receive lectures for not enforcing this rule. (online reflection)

When I asked the principal at my last practicum about children's first language, she told me, 'Oh, they don't use their mother language much here. Only to swear, and we pretend we don't' hear'. (online reflection)

I noticed in my practicum that there were a few students who had emigrated from the same country (Mexico) and they would often help one another by translating certain words or phrases. However, my partner teacher would interject and say 'In English please...we only speak English in this class.' (online reflection)

The pre-service teachers stated that even though in some schools 'English only' was not publicly promoted, in practice the partner teachers appeared to have a fear of different languages. A focus group reported that:

For those people who are unilingual I think they almost feel threatened sometimes or they feel out of their comfort zone. I think a lot of teachers struggle with that. (focus group) 
My partner teacher said: "I know the kids are saying stuff but I don't know what they're saying. I don't know if they are insulting me. I don't know if they're actually working." (focus group)

Some parents supported the 'English only' policy and practice. They believed that their children should speak only English, and discouraged the use of the first/home language:

We had a little guy in our class whose parents were English language learners. But they had that belief that we do not want to teach him our home language. So they would only speak to him in English at home and so his language skills were so underdeveloped compared to his cognitive abilities because his only exposure to language was in a language his parents don't naturally speak, so just all the complexities of language he was never exposed to from birth till age five when he came to kindergarten so you know it can have a pretty detrimental effect if things like that happen. (focus group)

In my class, we critiqued the monolingual principle (Howatt, 1984), which emphasizes “instructional use of the target language (TL) to the exclusion of students' home language (L1), with the goal of enabling learners to think in the TL with minimal interference from the L1" (Cummins, 2009, p. 317). Some teachers believe firmly that the student's first-language interferes with effective second-language learning, and school achievement. They believe that students should be taught exclusively in English in schools (Garcia-Navarez, Stafford \& Arias, 2005). This belief has been refuted by many scholars (Coelho, 2004; Cummins, 2009). However, the English only policy adopted in some schools suggests many administrators and teachers still strongly hold such a belief. For example, one pre-service teacher wrote: "I saw the English only policy being enforced several times and it became this taboo to be caught even whispering in any language other than English. I wasn't comfortable with that. It felt like I was taking away somebody's right to communicate" (online reflection). There is no empirical evidence to support the claim that English is best taught monolingually. Educators must abolish the damaging view that stamping out immigrant students' languages will somehow ensure educational success. They need to recognize students' first languages as an important component of their identity, a useful tool for thinking and learning, and a valuable medium for effective communication in the family and the community. 
Critiquing the "dominant discourses of schooling as an English monolingual, multicultural space" (Giampapa, 2010, p. 416), I invited pre-service teachers to examine their own attitudes toward EAL students' first language. Some pre-service teachers said that they were blind to EAL students' multilingual abilities. One wrote:

I don't view my students as bilingual or multilingual speakers. I view them all as children. I can't say that it crosses my mind to think of them in that way. (online reflection)

Others offered a good critique of the 'English only' policy in their practicum schools, but did not take sides in the ongoing debate which has continued in Canada and the US for a very long time. A few indicated that:

It seems to me that the emphasis in schools seems to get the students to speak English at the expense of their own language. It seems to be an either-or instead of both. (online reflection)

I think that effectively outlawing the use of native languages in a classroom or school only serves to make those languages seem shameful to the children who possess them. On the other hand, it could be exclusionary to the children and teachers who do not speak those languages. (online reflection)

Some pre-service teachers wanted to use students' first language, but were discouraged by their partner teachers since their partner teachers were not comfortable with students' first language:

I was asking this little boy if he would share his language but my partner teacher steered me right off that right away and you could tell that the other kids were getting excited they - half the class speaks another language but she didn't say but she actually directed the questions around it and I just felt that she wasn't comfortable delving into that area with the kids. (focus group)

Some bilingual pre-service teachers related to their own experience about how they felt their cultural identity was devalued when they were discouraged from speaking their first languages: 
In fact, I helped another ESL student in high school, of the same language translate a project and I was scorned for disruptive behaviour. In that moment I felt stripped of my culture and my identity and I thoroughly resented the school as a result of it. (online reflection)

When I was in the elementary school I was often one of two Asian students in the classroom and although I was not considered ESL, I never felt comfortable nor was I encouraged to speak my first language. If anything I was afraid to speak it because I was scared I would get in trouble by the teacher. This in turn made me feel ashamed of my first language and I remember feeling like school would be easier for me if I was Caucasian, which highly influenced my growing up as I hated speaking my native language and refused to practice it unless I was talking to my parents. This is a huge regret of mine because I don't speak my first language as well as I could have. I wish my teachers encouraged me to embrace my culture and language when I was a child or at least made me feel that my native language was important. (online reflection)

These pre-service teachers' own experience in school helped them identify with EAL students. As students it was obvious to them that their first languages were seen as inferior and their teachers did not encourage them to speak their first languages in school. They were caught in a situation that coercive relations of power that traditionally oppressed minority by subordinating the first languages of EAL students (Cummins, 2000).

\section{From monolingualism to multilingualism}

It is important for teacher educators to help pre-service teachers to shift their perceptions that multilingualism is a problem to be solved, instead of seeing it as a valuable resource. Concerns often expressed by teachers regarding the use of students' first languages in classrooms may, indeed, reflect their ideological beliefs (Karathanos, 2010). As Auerbach (1993, p. 10) notes, "whether or not we support the use of learners' L1 is not just a pedagogical matter: It is a political one, and the way that we address it in instruction is both a mirror of and a rehearsal for relations of power in the broader society." Accordingly, teacher educators need to guide future teachers to challenge their existing, often unacknowledged, beliefs and assumptions about students' first language use (e.g., the students' first language interferes with second language 
learning). A critical reflection via journaling processes, as well as, other means which include the use of dual-language books can be implemented. The written text is in both English and another language. In my class, I demonstrated how to use dual language books. I chose Story of the Chinese Zodiac (十二生肖的故事) by Monica Chang (1994) to read both in English and Chinese. Most of my students were not familiar with the story. It was also a good example to demonstrate how to provide background information, as well as, how to provide culturally relevant materials. This example illustrates how teachers can reconceptualize pedagogies that build on students' multilingual resources (Giampapa, 2010), whether or not, Chinese students are in the classroom.

I was aware that some pre-service teachers felt overwhelmed by the number of languages in the classroom. For instance, one pre-service teacher said:

It's quite overwhelming. There are so many things a teacher is dealing with. If the parents want to maintain the language, that's fine. I think it would be hard, like in my class there are so many kids and say 10 of them would speak another language at home, I don't know you could incorporate teaching them that. I don't know how I would do it. (focus group)

Ideally pre-service teachers should learn a second language. Even though they do not understand a second language, it is important for them to create a classroom environment that is open to different languages. I shared a story of a kindergarten teacher, a graduate student in my course, who invited parents from 11 different languages to be part of a family reading program in her classroom. Every Friday, she allocated 25 minutes for parent volunteers to read to small groups of children, often from dual-language books, on their own or with a partner parent reading the English text (Guo, 2012a). The teacher reported the increasing appreciation of the children toward their classmates' multilingual abilities, as well as how much the parents of these children valued the opportunity to share their first languages and be part of the learning community. This example validates the students' first language within the classroom. Furthermore, it challenges the colonial ideology associated with the superiority of speaking only one language, English, over speaking multiple languages (Yu, 2010). Validating students' first languages also challenges the ascribed subordinate status of many minority groups and affirms students' identities as being competent learners (Cummins, 2009). 
In addition to dual language books, we also explored the use of bilingual "identity texts" (Cummins, Bismilla, Cohen, Giampapa, \& Leoni et al., 2005). Identity texts refer to the product of student creative work or performances in which their identities are reflected in a positive light. For example, one student produced the following text (see Burwell \& Lenters, 2012, slide 8):

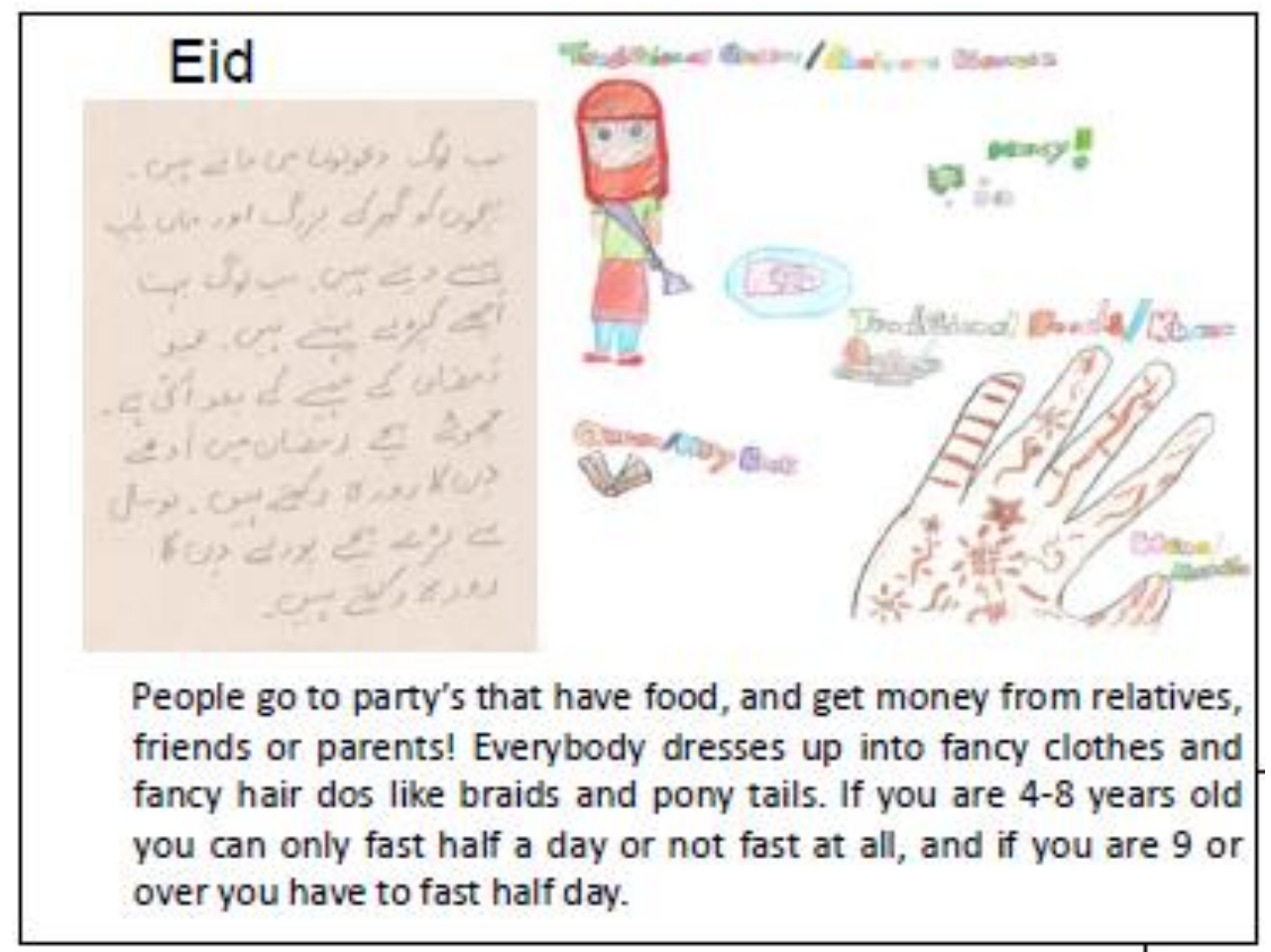

In the identity text project, EAL students, who were often, quite disengaged in writing in English, became so engaged that they did not want to leave the classroom for recess. One student stated in another study:

I wrote my story, I talked about my family, I practiced. I was practicing so much because I wished I could do good. I tried to balance stuff; I worked a long, long time, and my brother helped me. (Cummins \& Stille, cited in Gallagher \& Riviere, 2011, p. 12)

Through the demonstration of the effectiveness of dual language books and identity texts, I sought to engage student teachers to challenge monolingual and monocultural perspectives in education, and hopefully, to foster multilingual and multicultural approaches to teaching and learning that draw from the linguistic and cultural forms of capital and include identities of students' and their families (Bourdieu, 1991; Bourdieu \& Passeron, 1990). 
Some bilingual pre-service teachers became a role model for their students because they spoke more than one language:

I told my students that English is my second language and I was still learning. So all ESL students feel like they are very close to me and they started telling their language that what will you say this or how will you greet in your first language...I think appreciating or acknowledging that is their strength, because I told them if you know a second language, this is your strength. It is not your weakness. (focus group)

Some pre-service teachers started to consider incorporating the first language of their students:

In my future teaching, I would like to incorporate the first language of my students into their education. I am not sure exactly what I would do, but using grade 1 as an example, I would encourage parents to read with their children using books in their first language. I would also encourage parents to help their children with questions they have and review work that goes home, talking about it in both their first language and English. However, before any of this could be done, I would need to get the support of the parents. (online reflection)

Some pre-service teachers expressed the desire to use students' first language in their future teaching, but were uncertain how to do so. For example, one pre-service teacher stated:

I think when you talk about environment and particularly in Early Child Education (ECE) you talk about labeling everything, all of your play blocks and all of your buckets have labels on it. I think you could incorporate it that way by putting multilingual names on it, so having door in English, French, Chinese, whatever. I think those are small ways that you can do it, but on a huge scale, I don't know. (focus group)

Some shared experiences of how their partner teachers used their students' first language in math classes. For instance, one pre-service teacher reported:

My partner teacher has a great book. It was math games from different countries around the world, some from Africa and from Asia, all these different math games. There is culture within math you just have to really look deep into it to find it. (focus group) 
In my own classes, I encouraged students to share different math games. One student teacher brought a math card game from Italy. She showed us how to play the card game. In doing so, she taught us how to say simple Italian words and how to play the card game. Student teachers learned a practical strategy to move beyond labeling to engage students in different subjects such as math. In my teaching, I invited the pre-service teachers who speak different languages to count from 1 to 10 . This year, we counted in 11 different languages such as Cantonese, Mandarin, Spanish, Italian, German, Vietnamese, Dutch, Urdu, Punjabi, Nepali, and Japanese. I recorded these different languages with the expectation that the pre-service teachers could use it as a resource for their future teaching. I also hope that they will encourage their own students to do the same thing in their future teaching.

\section{Unlearning cultural privileges}

In response to the question about how pre-service teachers see their own culture, some Wonder whether they have a distinctive culture:

My family and my husband's family are all from the United Kingdom. We are all Caucasian, and we all speak English. We are part of the perceived majority group culture in Canada. So in that sense, I do sometimes feel that I don't have much of a culture because it is so common and accepted. (online reflection)

Others revealed their attitudes of resentment:

I sometimes feel my culture is overlooked as the focus is on minority groups and maintaining their culture...There are cultures where Canadian company will allow certain clothing of different cultures ensuring they are respected for that part of their culture... but then people are saying Happy Holidays during Christmas. That spirit of saying Merry Christmas is being pulled away and a part of my culture is disappearing to suit all cultures. I'm saddened inside as my culture is not being respected, it's just being taken away. (online reflection)

This statement revealed a belief in 'reverse racism', and some loss of cultural, social and religious power. They feel their unearned privileges are challenged. This white pre-service teacher, for example, expressed the discrepancy of different sets of expectations for people from 
visible cultural minority groups, and the mainstream. She complained that the spirit of saying Merry Christmas is being taken away, without realizing the significant influence of Christian holidays in the school in which its attitudes, practices, procedures, policies and its very structures privilege the dominant white EuroCanadian groups and at the same time, disadvantage members of visible minority groups who may not be Christians (hooks 1995).

Other pre-service teachers observed that diversity was not valued beyond a surface recognition of students' cultures:

You just won't get to the more deep beliefs or concerns or concepts of a culture, so it's very much the celebrations and the food is basically all you cover ...And especially in such a diverse school, where you know $70 \%$ of the children are from another country, there was very little of that showcased within the school. Both in the classrooms, in the artwork, in the events held, there was very little I found. (focus group)

As a result, some pre-service teachers recognized that EAL students were struggling with their cultural identity, but found it difficult to support their students' quests because they did not know how to do so:

I have a grade 2 student who is Canadian-born ESL and she speaks very fluent English. But I have seen a lot of evidences of a struggle with her culture and she doesn't really know where she's fitting in... Or she would lie and say she doesn't have lunch so we will buy her lunch in the cafeteria because she doesn't want to eat her noodles... We were doing fairy tales and we were doing a Chinese fairy tale and I was trying to connect it to her. I asked her if she could help me pronounce the names, maybe I was doing it wrong and she said, 'oh, I don't know. I'm not Chinese.' (focus group)

This grade 2 student felt ashamed to be publicly identified as being Chinese. She rejected her own cultural characteristics, including her Chinese lunch, and chose to distance herself from her ethnic group. Another pre-service teacher related this story to her own schooling experience: "During my school years, I never told anyone about my father or my Turkish heritage as I was afraid that I would be ridiculed" (online reflection). Goodwin (1997, p. 126) referred to this behaviour as internalization: "it is a consequence of rejection whereby people who are marginalized and excluded begin to see themselves in those terms and to define others of color in 
those terms as well." This incident made the pre-service teacher think about how she will explore the concept and reality of identity in her own classroom:

I think that in my class if I could investigate identity. What does it mean? What is our idea of identity and all the different parts that come in there? So that she would understand there are many different parts to your identity. You're not just one thing. She doesn't have to choose between Canadian and Chinese and she can be proud of that and bring it into herself. (focus group)

I have one Arabic boy who has been difficult to get through to - in lots of ways he is disrespectful. I would interpret that as 'he doesn't respect me because I am a woman, and that is part of his culture,' but honestly, although it has taken some work on my part to befriend this boy, as he has gotten to know me over the past couple of months, he has come to respect me - so I believe I can overcome that cultural barrier through relationship. (online reflection)

In my teaching, I invited student teachers to see beyond the "heroes and holidays" approach to culture to recognize that culture embraces language, identity, relationships, beliefs and ways of knowing and learning (Lee, Menkart, \& Okazawa-Rey, 2007). It is important for student teachers to critically examine the cultural contexts that influenced the development of their own attitudes and beliefs (Mujawamariya \& Mahrouse 2004; Solomon and Levine-Rasky 2003). Some pre-service teachers are able to understand their own privileges. One stated that 'much of my culture is based on European traditions brought over to Canada years ago. This has largely focused on Christian holidays, values and beliefs that have strongly influenced how I think' (online reflection). They are able to understand their own biases such as 'my way of doing things was normal' (online reflection). Hopefully, such self-awareness helps them to "challenge Eurocentric beliefs and practices and move from a position that assumes a singular, monocultural reality, to adopting a worldview that is respectful of multiple belief systems" (Guo, Arthur \& Lund, 2009, p. 574).

\section{Naming racism}

In addition to linguistic and cultural diversity, the local school board had students from different racial backgrounds. However, many pre-service teachers were reluctant to engage in 
discussion of race and racism, a phenomenon noted by other researchers (Egbo, 2011; Milner, 2006; Pollock, 2001). Being mindful that how teachers construct race impacts significantly their practice and their interactions with students, I invited student teachers to pay attention to racial discrimination in their field experience. Reflecting on their own practicum experiences, some pre-service teachers noticed that EAL children were excluded by their peers in the classroom:

In some group activities and games, some new immigrant children in our class were discriminated by their classmates likely because they were new and also because they couldn't speak much English; other children didn't want to be in the same group with them. (online reflection)

Some pre-service teachers chose to remain silent about racist remarks:

There was a recent incident that occurred in my school where one child discriminated against another child. The first child called the other child 'weird' because of his race (he explicitly said you are weird because you are $\mathrm{xxx}$ ). (online reflection)

A teacher got very angry at a Muslim boy who she perceived as being disrespectful of a female student in the class, and in her outburst, called him a pig. (online reflection)

I actually heard some teachers make racist remarks to boys who have a turban. I didn't say anything because I didn't want to rock the boat. (online reflection)

The above quotes show individual expressions of racist prejudice based on the intersection of race, language, and culture (Kubota, 2015). These pre-service teachers were uncomfortable to disrupt the racialized statements. They did not want to "rock the boat" and retreated to silence. Edbo (2011, p. 32) referred to this behaviour as "engaging the discourse of silence" about racism. Keeping silent about issues of race will make them complicit in the perpetuation of individual and institutional racism.

One student teacher participant blamed the failure of EAL students for their lack of working hard:

If they (EAL students) weren't learning English, it was because they weren't doing enough; they needed to study harder, they needed to take initiative entirely on their own 
to approach others, and so on. 'If I can speak English, then so can they!' (online reflection)

Many of the pre-service student teachers shared a similar attitude: individual merit, ability, and effort meant success. They failed to recognize that possession of 'non-merit', inherited factors, such as wealth, social and cultural capital, and other social conditions give some groups privilege over others (Dei, 2008). They failed to recognize that the school generates its attitudes, practices and structures which can privilege the dominant white group and may disadvantage members of visible minority groups (Hooks, 1995). By not realizing the impact of school culture and other socio-cultural conditions, some student teachers, effectively removed themselves from the systemic change process.

Other pre-service teachers noticed that there was a lack of systemic support for EAL students. According to one pre-service teacher:

In my practicum school, $70 \%$ of the children are from another country. At the beginning of the year they had a funding cutback, and the first thing they did was to eliminate the ESL teacher. (focus group)

In my classes we discuss how current fiscal provisions privilege some groups and create inequalities (Young, 1995, 2008). In 2013, Alberta Education reduced EAL funding to five years, down from seven years previously (Alberta Education, 2013a). This funding cap for additional support is the "most recent example of a systemic, structural barrier to equitable treatment" (McCarthy \& Foxx, 2001, p. 6). EAL learners present a wide range of needs, such as refugees who may have never attended school prior to immigrating and who take more than five years to acquire academic English. Yet, interestingly, there are no similar caps on financial support of Learning Assistance, or Gifted Education (Wild et al., 2007). Funding for EAL services in Alberta is not targeted to meet the needs of minority students. Accordingly, funding can be redirected to other expenses such as utilities and maintenance (Wild et al., 2007). There are no spending requirements concerning the $\$ 1178.10$ allocated provincially, for each eligible EAL student, in the Alberta school districts (Alberta Education, 2013b). In fact, enhanced funding was discontinued in September 2011 (Alberta Education, 2011). In these ways, the current funding policies, in fact, set the grounds for potential educational inequities and abuses. 


\section{Summary of Strategies}

Bearing in mind information from the literature and previous study, the following strategies and activities can be used to support and encourage pre-service teachers to work effectively and equitably in a linguistically, culturally and racially diverse school context. Strategies include:

- Adopting a language shock activity to challenge pre-service teachers to better understand what it feels like to be an EAL student;

- Discussing the essay "Mother Tongue" by Amy Tan (1990) in order to challenge accent discrimination and the limited perceptions of "broken English";

- Discussing Amy Tan's (1989) novel, The Joy Luck Club to gain a better understanding of immigration experiences, and as importantly, to understand the value of immigrant parents' aspirations for their children;

- Inviting pre-service teachers to examine their own attitudes toward EAL students' first language in order to, challenge their monolingual thinking;

- Demonstrating how to use dual language books by reading for example, the Story of the Chinese Zodiac by Monica Chang (1994) in English and Chinese to illustrate multilingual practices;

- Sharing the experience of the teacher who invited parents, grandparents, and community members to her classroom to read dual language books to students in order to, demonstrate multilingual practices;

- Inviting pre-service teachers to count in different languages to validate the multilingual abilities of their future students;

- Incorporating a student's original identity text in English and Urdu in order to build on their future students' linguistic capital;

- Inviting pre-service teachers to share math games from different cultures to demonstrate how to integrate some aspects of their future students' cultures in several subjects. 


\section{Conclusion}

These strategies can be used by other teacher educators. Ways of working with linguistically and culturally diverse learners should be woven throughout teacher education programs (Vanthuyne \& Clark, 2015). Accordingly, teacher education programs in today's highly diverse immigration contexts must be reconceptualized. It is essential to address what it means to teach in multilingual, multicultural, and multiracial schools. Further to the development of interlinguistic and intercultural competences, I argued elsewhere (Guo, Arthur \& Lund, 2009), that it is necessary to implement antiracism education in teacher education so as to overcome an underlying but pervasive fear of difference. The label of difference should be deconstructed and reconstructed. There is a need to move from viewing differences as deficits to understanding and appreciating differences as the most fundamental trait of humanity. Such differences, are positive, and enrich our lives (Abdi, Shultz, \& Purton, 2012). From this perspective, educators need to see immigrant students as capable of achieving their potential, and their well-being. From this perspective, it is important to understand the significant knowledge possessed by many EAL students, including their linguistic and cultural backgrounds. It is important for teacher educators to help pre-service teachers to shift their representations of multilingualism from being 'a problem to be solved,' to seeing students as being intelligent, and resourceful, who know how to navigate, and survive difficult life challenges. Pre-service teachers need to unlearn their privileges. They need to recognize and make use of the knowledge of immigrant students. It is also important for teacher educators to support pre-service teachers in developing a critical awareness of cultural and racial discrimination, and the deep seated school policies, attitudes and beliefs which underlie it. 


\section{References}

Abdi, A., Schultz, L., \& Purton, F. (February 23, 2012). Do we know our new students? Social justice, global citizenship and the dignity of difference. Workshop conducted at the Conference of the Western Canadian Association for Student Teaching (WestCAST), Calgary, Alberta, Canada.

Alberta Education. (2011). Funding manual for school authorities 2011/2012 school year.

Retrieved from http://education.alberta.ca/media/6432970/2011\%202012\%20funding\%20manual.pdf

Alberta Education. (2013a). Funding manual for school authorities 2013/2014 school year.

Retrieved from http://education.alberta.ca/media/7407830/2013-

2014\%20funding\%20manual-updated.pdf

Alberta Education. (2013b). Funding manual for school authorities 2013/2014 school year.

Retrieved from http://education.alberta.ca/media/7407830/2013-

2014\%20funding\%20manual-updated.pdf

Auerbach, E.R. (1993). Reexamining English only in the ESL classroom. TESOL Quarterly, 27, 9-32.

Butt, E.G. (2008). Teachers' perception of ELL education: Potential solutions to overcome the greatest challenges. Multicultural Education, 15(3), 39043.

Bismilla, V., Cohen, S., Giampapa, F., \& Leoni, L. (2005). Timelines and lifelines: Rethinking literacy instruction in multilingual classrooms. Orbit, 36(1), 22-26.

Bourdieu, P. (1991). Language and symbolic power (G. Raymond \& M. Adamson, Trans.). Oxford, UK: Polity Press.

Bourdieu, P., \& Passeron, J. C. (1990). Reproduction in education, society and culture (R. Nice, Trans. [2nd ed.]). London, UK: Sage Publications.

Bruner, J.S. (1986). Actual minds: Possible worlds. Cambridge, MA: Harvard University Press.

Burwell, C., \& Lenters, K. (September 28, 2012). Lectures of literacy, language and culture in the K-12 classroom. Calgary: University of Calgary.

Chang, M. (1994). Story of the Chinese Zodiac. Taipei, Taiwan: Yuan-Liou Publishing.

Coelho, E. (2004). Adding English: A guide to teaching in multilingual classrooms. Toronto, ON: Pippin. 
Cummins, J. (2000). Language, power and pedagogy: Bilingual children in the crossfire. Clevedon, UK: Multilingual Matters.

Cummins, J. (2009). Multilingualism in the English-language classroom: Pedagogical considerations. TESOL Quarterly, 43(2), 317-321.

Cummins, J., Bismilla, V., Chow, P., Cohen, S., Giampapa, F., Leoni, L., et al. (2005). Affirming identity in multilingual classrooms. Educational Leadership, 63(1), 38-43.

Cummins, J., \& Stille, S. (2011). Engaging literacies: Identity texts as catalyst and medium for academic performances. In K. Gallagher \& D. Rivière. Putting inner city students first: A school-university partnership (pp. 10-13). Toronto: Centre for Urban Schooling.

Dei, G. (2008). Racist beware: Uncovering racial politics in the postmodern society. Rotterdam: Sense Publishers.

Egbo, B. (2011). What should preservice teachers know about race and diversity? Exploring a critical knowledge-base for teaching in 21 st century Canadian classrooms. Journal of Contemporary Issues in Education, 6(2), 23-37.

Flores, B.B., \& Smith, H. L. (2009). Teachers' characteristics and attitudinal beliefs about linguistic and cultural diversity. Bilingual Research Journal, 31(1/2), 323-358.

Garcia-Navarez, A.g., Stafford, M.E., \& Arias, B. (2005). Arizona elementary teachers' attitudes toward English language learners and the use of Spanish in the classroom instruction. Bilingual Research Journal, 29(2), 295-317.

Giampara, F. (2010). Multiliteracies, pedagogy and identities: Teacher and student voices from a Toronto elementary school. Canadian Journal of Education, 33(2), 407-431.

Goodwin. A. L. (1997). Multicultural stories: Preservice teachers' conceptions of and responses to issues of diversity. Urban Society, 32(1), 117-145.

Goodwin, A. L., \& Macdonald, M. (1997). Educating the rainbow: Authentic assessment and authentic practice for diverse classrooms. In A. L. Goodwin, (Ed.), Assessment for equity and inclusion: Embracing all our children (pp. 211-228). New York: Routledge.

Guo, S. (2009). Difference, deficiency, and devaluation: Tracing the roots of non/recognition of foreign credentials for immigrant professionals in Canada. Canadian Journal for the Study of Adult Education, 22(1), 37-52.

Guo, Y., Arthur, N., \& Lund, D. (2009). Intercultural inquiry with pre-service teachers. Intercultural Education, 20(6), 565-577. 
Guo, Y. (2012a). Diversity in public education: Acknowledging immigrant parent knowledge. Canadian Journal of Education, 35(2), 120-140.

Guo, Y. (2012b). Exploring linguistic, cultural, and religious diversity in Canadian schools: Preservice teachers' learning from immigrant parents. Journal of Contemporary Issues in Education, 7(1), 4-23.

Guo, Y. (in press). Pre-service teachers and Muslim parents: Exploring religious diversity in Canadian public schools. Diaspora, Indigenous, and Minority Education.

hooks, b. (1995). Killing rage, ending racism. New York: Henry Holt.

Karathanos, K.A. (2010). Teaching English language learner students in the U.S. mainstream schools: Intersections of language, pedagogy, and power. International Journal of Inclusive Education, 14(1), 49-65.

Kubota, R. (2015). Race and language learning in multicultural Canada: Towards critical antiracism. Journal of Multilingual and Multicultural Development, 36(1), 3-12.

Lee, E., Menkart, D, Okazawa-Rey, M. (Eds.). (2007). Beyond heroes and holidays: A practical guide to K-12 antiracist, multicultural education and staff development. Washington, DC: Teaching for Change.

McCarthy, V., \& Foxx, V. (2001). ESL: Time to remove the funding cap. Teacher, 13 (May/June), 6.

Miles, M., Huberman, M., \& Saldaña, J. (2014). Qualitative data analysis: A methods sourcebook (3rd ed.). Sage: Los Angeles.

Milner, H. (2006). Preservice teachers' learning about cultural and racial diversity: Implications for urban education. Urban Education, 41(4), 343-375.

O’Neal, D.D., Ringler, M., \& Rodriguez, D. (2008). Teachers' perception of their preparation for teaching linguistically and culturally diverse learners in rural eastern North Carolina. The Rural Educator, 30(1), 2-13.

Pollock, M. (2001). How the question we ask most about race in education is the very question we most suppress. Educational Researcher, 30(9), 2-12.

Solomon, R.P., Portlli, J.P., Daniel, B. \& Campbell, A. (2005). The discourse of denial: How white teacher candidates construct race, racism and 'white privilege'. Race, Ethnicity and Education, 82(2), 147-169.

Tan, Amy. (1989). The Joy Luck Club. New York: Ivy Books. 
Tan, Amy. (1990). Mother tongue. The Threepenny Review, 43, 7-8.

Vanthuyne, A., \& Clark, J. (2015). Teaching for change and diversity. In L. Thomas \& M. Hirschkorn (Eds.), Change and progress in Canadian teacher education: Research on recent innovations in teacher preparation in Canada (pp. 525-549). Canadian Association for Teacher Education.

Wild, J., Helmer, S., Tanaka P., \& Dean, S. (2007). A ‘crisis in ESL education' in BC schools. Retrieved from http://bctf.ca/eslpsa/

Young, I. (1995). Polity and group difference: A critique of the ideal of universal citizenship. In R. Beiner (Ed.), Theorizing citizenship (pp. 175-207). Albany: State University of New York.

Young, I. (2008). Justice and the politics of difference. In S. Seidman \& J. Alexander (Eds.), The new social theory reader (pp. 261-269). London: Routledge.

Yu, H. (February 1, 2010). Vancouver's own not-so-quiet revolution. Vancouver Sun.

\footnotetext{
${ }^{i}$ The quotes are taken from a larger study of Knowledge Construction of ESL Parents and Pre-Service Teachers and its Mobilization, funded by Social Sciences and Humanities Research Council (SSHRC), in which the research methodology, and research findings are fully documented (see Guo, 2012a, 2012b, in press).
} 